\title{
The Study of Microwave and Electric Hybrid Sintering Process of AZO Target
}

\author{
Ling-yun Han, Yong-chun Shu, Yang Liu, Lu Gao, Qing-tong Wang, and Xiao-na Zhang \\ The Key Laboratory of Weak Light Nonlinear Photonics, Ministry of Education, Nankai University, Tianjin 300457, China \\ Correspondence should be addressed to Yong-chun Shu; shuyc@nankai.edu.cn
}

Received 9 November 2015; Revised 1 February 2016; Accepted 17 February 2016

Academic Editor: Philip Eisenlohr

Copyright ( 2016 Ling-yun Han et al. This is an open access article distributed under the Creative Commons Attribution License, which permits unrestricted use, distribution, and reproduction in any medium, provided the original work is properly cited.

\begin{abstract}
We simulated the microwave sintering of $\mathrm{ZnO}$ by $3 \mathrm{D}$ modelling. A large-size $\mathrm{Al}$-doped $\mathrm{ZnO}$ (AZO) green ceramic compact was prepared by slurry casting. Through studying the microwave and electric hybrid sintering of the green compact, a relative density of up to $98.1 \%$ could be obtained by starting microwave heating at $1200^{\circ} \mathrm{C}$ and increasing the power 20 min later to $4 \mathrm{~kW}$ for an $\mathrm{AZO}$ ceramic target measuring $120 \times 240 \times 12 \mathrm{~mm}$. The resistivity of AZO targets sintered with microwave assistance was investigated. The energy consumption of sintering could be greatly reduced by this heating method. Until now, few studies have been reported on the microwave and electric hybrid sintering of large-size AZO ceramic targets. This research can aid in developing sintering technology for large-size high-quality oxide ceramic targets.
\end{abstract}

\section{Introduction}

Because of the high optical transmittance and low resistivity of transparent conducting oxide (TCO), TCO films are applied in many electronic devices such as solar cells, flat displays, and touch panels [1-4]. Indium tin oxide (ITO) is currently the most popular industrial TCO film material. However, because of the shortage and high cost of In as a resource, an alternative must be found. Some researchers have found $\mathrm{Al}$-doped $\mathrm{ZnO}$ (AZO) film to be a potential alternative to ITO, with optical and electrical properties approaching those of the conventional material [5-7].

Magnetron sputtering is the main fabrication technology used for industrial TCO films. The method requires oxide ceramic feed materials with the same components and quality as the sputtering target. Sintering, as the most important step in preparing the target, has been studied by many researchers, but most studies have investigated electricity as the sintering power [8-12]. The obvious drawbacks of this method include power wastes and the possibility of cracking the ceramic target, as the temperature distribution is not homogeneous during sintering.

Microwave energy is a new sintering power that may increase sintering speed and homogeneity while decreasing the energy cost [13-15]. The working theory is that microwave radiation causes the electric dipole moment rotation of the polar molecules in the dielectric materials, converting the electromagnetic energy to heat energy instantaneously, rapidly, and efficiently. Gunnewiek and Kiminami studied the effect of microwave heating rate on the sintering of $\mathrm{ZnO}$, indicating that the relative density of microwave sintered $\mathrm{ZnO}$ was independent of the heating rate, but the grain growth could be restricted by heating rates with a lower time and energy requirement [16]; Birnboim et al. studied the influence of microwave frequency on $\mathrm{ZnO}$ sintering, indicating that the temperature gradients could be reduced by changing the microwave frequency [17], while the research of Janney et al. revealed microwave radiation enhanced sintering of ceramic compacts, including lower sintering temperatures and reduced activation energies $[18,19]$. However, the limit of microwave sintering research above is obvious: the compacts in the experiments are all in millimeter size, which is too small for industry. The size of AZO targets required for industry is usually beyond $100 \times 200 \times 10 \mathrm{~mm}$.

This study addresses the technology of microwave and electric hybrid sintering to prepare large-size $(\geq 100 \times 200 \times$ $10 \mathrm{~mm})$ AZO ceramic targets with high density $(\geq 98 \%)$ for magnetron sputtering. 


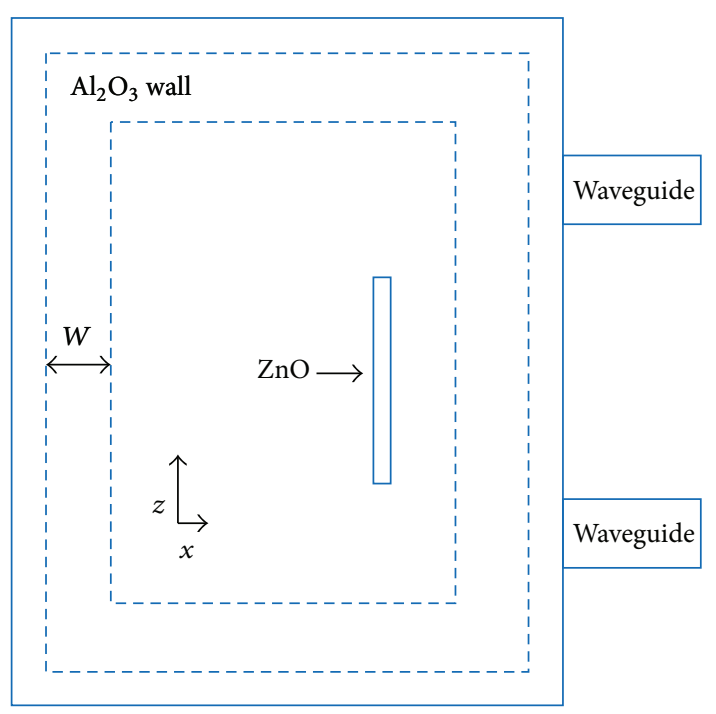

(a)

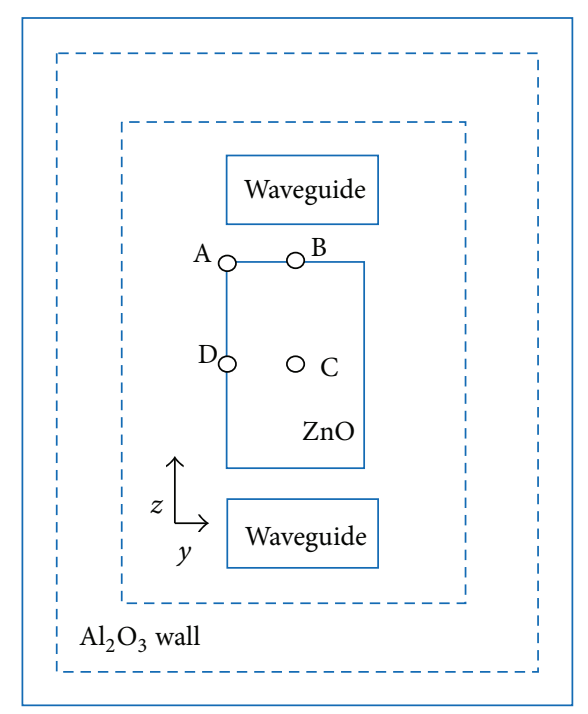

(b)

FIGURE 1: Cross-sectional view of the microwave sintering apparatus, (a) the $x$ - $z$ plane view, (b) the $y$ - $z$ plane view.

\section{Simulation of the Microwave Sintering Process}

In this study, the finite element method (FEM) [20] is applied to simulate microwave sintering using COMSOL software. By setting the physical parameters of the microwave transmitter and the $\mathrm{ZnO}$ samples and investigating the sintering process with single- and double-source microwave transmitters, we obtain the distributions of temperature and electric field during sintering. Electromagnetic field equation (1), heat transport equation (2), and electromagnetic power equation (3) are as follows:

$$
\begin{aligned}
\nabla^{2} E+k^{2} \cdot E & =0, \\
\rho(T) C(T) \frac{\partial T}{\partial \tau} & =\lambda(T) \nabla^{2} T+P, \\
P & =\frac{1}{2} 2 \pi f \varepsilon_{0} \varepsilon^{\prime \prime}(T)|E|^{2} .
\end{aligned}
$$

In the equations $\rho, C$, and $\lambda$ are density, capacity, and thermal conductivity, respectively; $f$ is the working frequency, the complex permittivity $\varepsilon=\varepsilon^{\prime}-j * \varepsilon^{\prime \prime}$, and the propagation vector of the electromagnetic wave $k=2 \pi f\left(\mu_{0} \varepsilon_{0} \varepsilon\right)^{1 / 2}$.

2.1. Model and Simulation. Figure 1 depicts the configuration of the microwave furnace including the sample, as used in our study. The cavity volume of the microwave furnace is $420 \times$ $420 \times 420 \mathrm{~mm}$. The $86 \times 43 \mathrm{~mm}$ waveguide ports are excitation sources in the $\mathrm{TE}_{10}$ mode, and the operating frequency is $2.45 \mathrm{GHz}$. The total output power of the microwave is $10 \mathrm{~kW}$. Two equally sized ports are placed in the $y-z$ plane of the cavity. To reduce heat loss and protect the wall of the cavity, a porous $\mathrm{Al}_{2} \mathrm{O}_{3}$ sheet is introduced as insulation; the gap between the outer boundary of the sheet and the cavity wall is $20 \mathrm{~mm}$. The thickness $W$ is $40 \mathrm{~mm}$, and the $\mathrm{ZnO}$ sample in the furnace has a volume of $10 \times 10 \times 100 \mathrm{~mm}$. During the simulation, the sample is perpendicular to the half-height surface and the locations of the two microwave ports have mirror symmetry relative to the half-height surface. Labels A, $\mathrm{B}, \mathrm{C}$, and $\mathrm{D}$ designate reference points at four different positions. The parameters of the porous $\mathrm{Al}_{2} \mathrm{O}_{3}$ and $\mathrm{ZnO}$ including complex permittivity $\varepsilon$ (a.u.), density $\left(\mathrm{g} / \mathrm{cm}^{3}\right)$, specific heat capacity $C_{p}(\mathrm{~J} /(\mathrm{g} \cdot \mathrm{K}))$, and heat transfer coefficient $K_{p}$ $\left(\mathrm{W} /\left(\mathrm{m}^{2} \cdot{ }^{\circ} \mathrm{C}\right)\right)$ are shown in Table 1.

We selected air as the sintering atmosphere in the cavity and copper as a perfect cavity wall. The penetration of the electromagnetic field into the sample is characterized by the skin depth $\delta$, given by (4) [21]. The permittivity and $\delta$ of the $\mathrm{ZnO}$ sample vary with temperature, as shown in Figure 2. Consider

$$
\delta=\frac{c}{\sqrt{2} \pi f \sqrt{\sqrt{\left(\varepsilon^{\prime}\right)^{2}+\left(\varepsilon^{\prime \prime}\right)^{2}}-\varepsilon^{\prime}}},
$$

where $c$ is the speed of light.

\subsection{Results and Discussion of Simulation}

2.2.1. Electric Field Distribution. The total output power was $10 \mathrm{~kW}$. Each port for the double-source microwave had an output power of $5 \mathrm{~kW}$ in the simulation. By comparing the output power of the single- and double-source microwave ports, we obtain the electric field distributions from the single- and double-source microwave transmitter ports, as shown in Figure 3. Although the dimension of the electric field does not differ between the double- and single-source microwaves, the intensity of the field produced by the doublesource microwave is significantly higher and the crosssectional symmetric conditions in both the $y$ and $z$ directions are satisfied by the double-source microwave, which greatly reduces the load on memory and computation. 
TABLE 1: Relevant parameters of $\mathrm{ZnO}$ and $\mathrm{Al}_{2} \mathrm{O}_{3}$.

\begin{tabular}{|c|c|c|}
\hline & $\mathrm{Al}_{2} \mathrm{O}_{3}$ & $\mathrm{ZnO}$ \\
\hline$\varepsilon$ (a.u.) & $4.5-j \cdot 0.0001$ & See details in Figure 2 \\
\hline$\rho\left(\mathrm{g} / \mathrm{cm}^{3}\right)$ & 0.24 & $\begin{array}{c}\rho / \rho_{\text {th }}=0.52\left(\text { for } T \leq 600^{\circ} \mathrm{C}\right) \\
\rho / \rho_{\text {th }}=1-\exp [-0.00586(T-463.7)]\left(\text { for } 600^{\circ} \mathrm{C}<T \leq 1150^{\circ} \mathrm{C}\right) \\
\rho / \rho_{\text {th }}=0.776+0.1792 * 10^{-3} T\left(\text { for } T>1150^{\circ} \mathrm{C}\right)\end{array}$ \\
\hline$C_{p}(\mathrm{~J} /(\mathrm{g} \cdot \mathrm{K}))$ & 1.09 & $C_{p}=-9880 / T^{2}+7.34 * 10^{-3} T+0.58$ \\
\hline$K_{p}\left(\mathrm{~W} /\left(\mathrm{m}^{2} \cdot{ }^{\circ} \mathrm{C}\right)\right)$ & $\begin{array}{l}8 * 10^{-4}+8 * 10^{-7}(T-500) \text { for } T \leq 500^{\circ} \mathrm{C} \\
8 * 10^{-4}+16 * 10^{-7}(T-500) \text { for } T>500^{\circ} \mathrm{C}\end{array}$ & $\begin{array}{l}\text { Low temperature stage: } K_{p} \geq 2.67 * 10^{-2} \\
\text { High temperature stage: } K_{p}=5.34 * 10^{-3}(T / 520)^{2.5} \\
\qquad T>1100^{\circ} \mathrm{C}: K_{p}=0.0348\end{array}$ \\
\hline
\end{tabular}

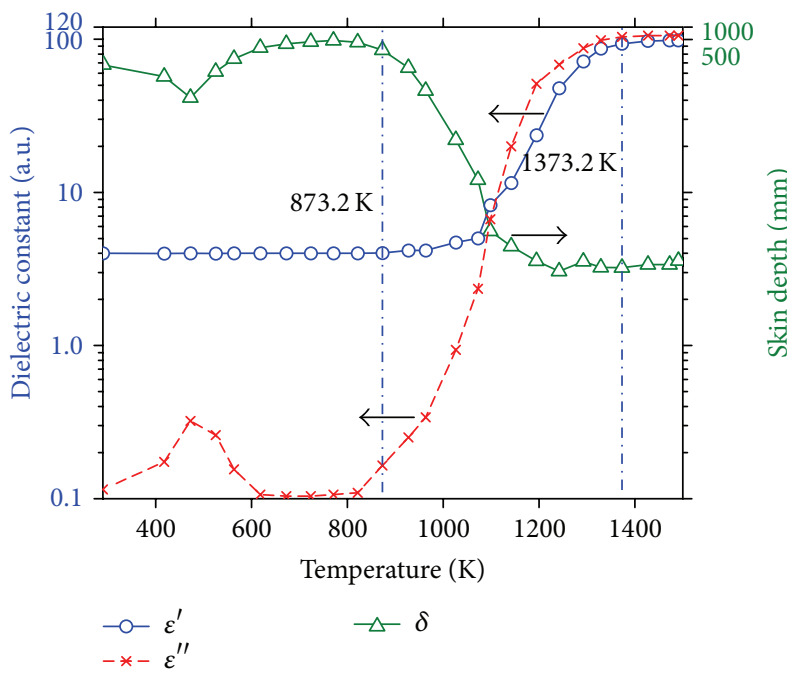

FIGURE 2: Real and imaginary parts $\varepsilon^{\prime}$ and $\varepsilon^{\prime \prime}$ of the complex dielectric constant and the skin depth $\delta$ of $\mathrm{ZnO}$ versus temperature $T$ at $2.45 \mathrm{GHz}$.

2.2.2. Temperature Field Distribution. The single- and double-source microwave power was set to $10 \mathrm{~kW}$ and $5 \mathrm{~kW}$, respectively, which ensured the same total output power. The initial temperature and density of the $\mathrm{ZnO}$ sample was $25^{\circ} \mathrm{C}$ and $2.917 \mathrm{~g} / \mathrm{cm}^{3}$, respectively.

When the temperatures of the four reference points all reached or exceeded $1200^{\circ} \mathrm{C}$, we terminated the simulation. The temperature changes of the four locations are plotted in Figure 4. Obvious differences in temperature occur among the four reference points at temperatures below $1000^{\circ} \mathrm{C}$. However, these differences decrease gradually as the temperature increases. Eventually, the temperatures of all points equalize above $1000^{\circ} \mathrm{C}$. This indicates that microwave sintering may be more homogenous at high temperatures. Additionally, singlesource microwave sintering requires more time to reach $1100^{\circ} \mathrm{C}$ than the double-source system. With respect to energy utilization, double-source microwave sintering will be more effective and practical than single-source.

The simulation was the first time to use a $3 \mathrm{D}$ model to illustrate the microwave sintering process. It was closer to practical sintering process with the insulation and dynamic parameters introduced in the simulation. Though the simulation has some difference with the experiment because of the limit of computational ability, the results have shown us the possibility of getting a bigger homogeneous sintering area for solving the cracking problem in the preparation of big-size ceramic target by setting multisource microwave. Part of the furnace in the experiments was designed by the simulation.

\section{Experimental}

The $\mathrm{ZnO}$ and $\mathrm{Al}_{2} \mathrm{O}_{3}$ powders used in the experiment were nanosized particles; ammonium polyacrylate, polycarboxylate superplasticizer, and arabic gum were used as the dispersant, surface active agent, and binder, respectively. All the materials used were analytical reagent (AR). The AZO ceramic targets were prepared by sintering the AZO green compacts. The process consisted of several steps: (1) the $\mathrm{ZnO}$ and $\mathrm{Al}_{2} \mathrm{O}_{3}$ powders were mixed in mass ratio of $98: 2$ by ball-milling for $2 \mathrm{~h}$ and then poured into a solution of distilled water, dispersant, surface active agent, and blinder in the volume ratio of $50: 1.2: 0.8: 0.5$. (2) After ball-milling in vacuum for $2 \mathrm{~h}$, white slurries with proper viscosity and fluidity were obtained. (3) The slurries were poured into the plaster mold and allowed to consolidate for $48 \mathrm{~h}$ at $25^{\circ} \mathrm{C}$. (4) The wet green compacts were placed into a drying oven for 1 week at $80^{\circ} \mathrm{C}$. After the thermal treatment at $500^{\circ} \mathrm{C}$ to remove the water and chemical reagents, we obtained dried AZO green compacts of $170 \times 340 \times 17 \mathrm{~mm}$.

The green compacts were then electrically heated at $1^{\circ} \mathrm{C} / \mathrm{min}$ to the setting temperatures $(1000,1100,1200$, and $1300^{\circ} \mathrm{C}$ ), after which microwave heating was started. The output power of the microwave was varied from 1 to $5 \mathrm{~kW}$ and the change rate of power varied from $0.16 \mathrm{~kW} / \mathrm{min}$ to $0.8 \mathrm{~kW} / \mathrm{min}(5-25 \mathrm{~min})$. The rectangular bulk AZO at the size of $120 \times 240 \times 12 \mathrm{~mm}$ was obtained after heating by electricity and microwave for $3 \mathrm{~h}$ at $1460^{\circ} \mathrm{C}$.

Figure 5 shows a schematic view of the furnace, which was self-designed and made by Gaoge Thermal Treatment, Inc., Hefei, China. Resistance rods were located around the inner wall of the furnace, which produced heat by electricity. Eight microwave transmitters of the same standard were distributed symmetrically at the top of the furnace, which provided a stable, uniform, and freely controlled electromagnetic field. The frequency was $2.45 \mathrm{GHz}$ and the maximum power of each transmitter was $1 \mathrm{~kW}$. The theoretical density of AZO target in the experiment was $5.56 \mathrm{~g} / \mathrm{cm}^{3}$. The densities 


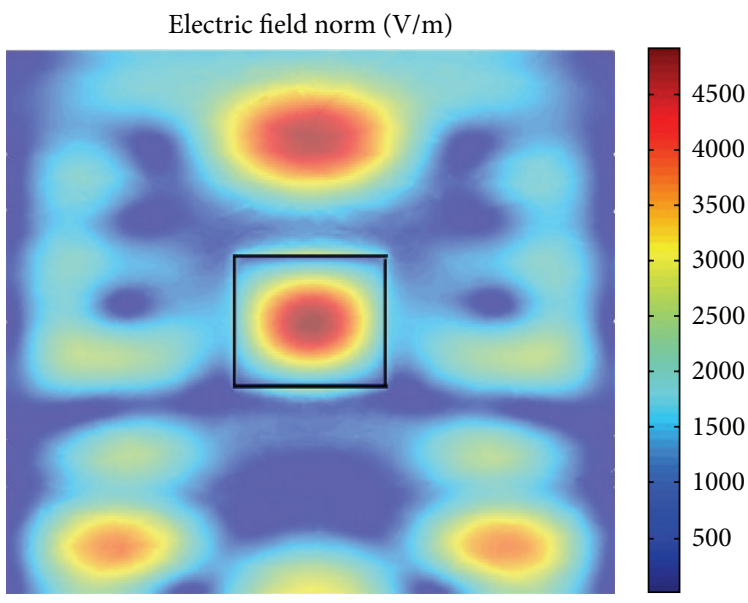

(a)

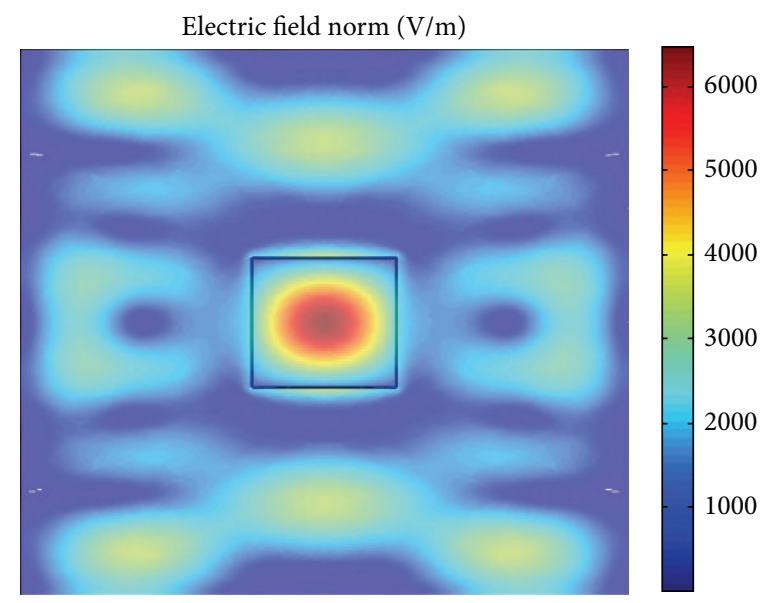

(b)

FIGURE 3: Surface plots of microwave electric field distribution for (a) single-source and (b) double-source microwave ports.

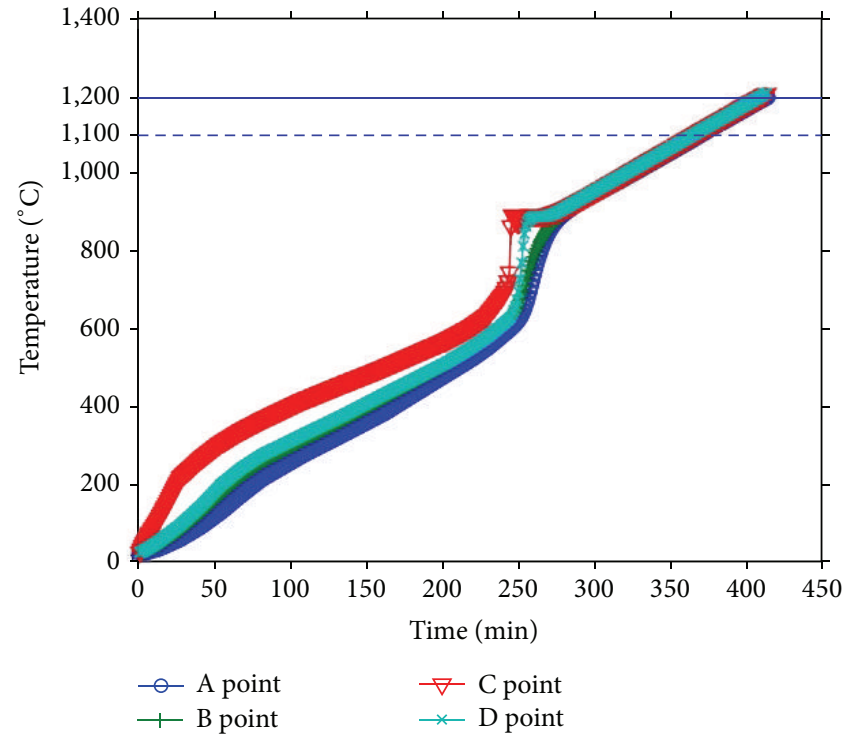

(a)

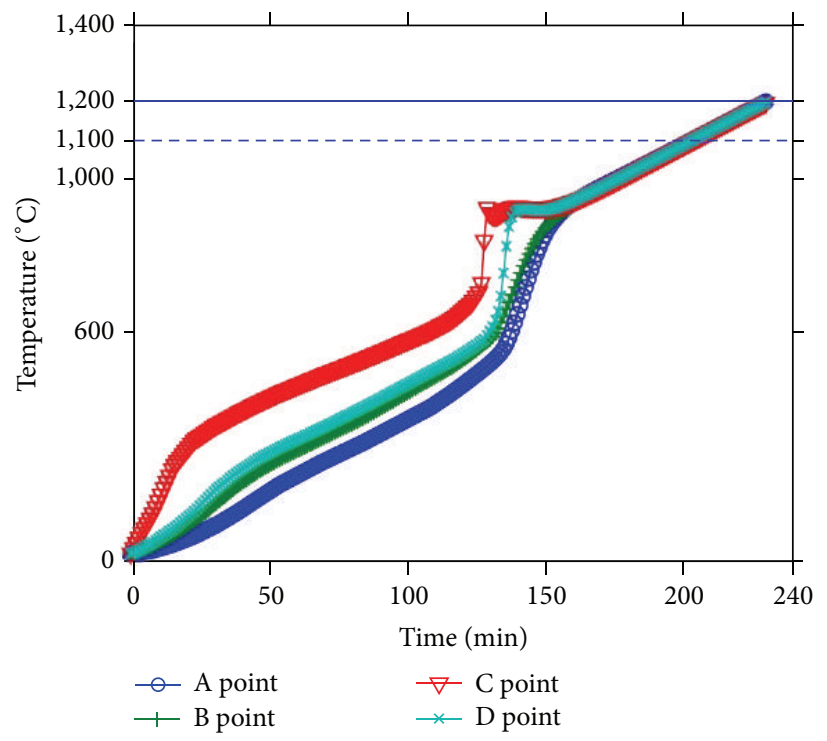

(b)

FIGURE 4: Plots of temperatures of four reference points versus heating time in the microwave heating process for (a) single-source and (b) double-source microwave output.

of the targets were measured based on Archimedes' principle. The microstructures and morphologies were observed by a Leo 1530vp scanning electron microscope (SEM). The resistivity of the sintered targets was tested by a four-point probe method (ST2258A, Jingge Electronic Co., Suzhou, China).

\section{Results and Discussion}

4.1. Effect of Microwave Starting Temperature on the Microstructure and Density of AZO Target. Figure 6 shows $\mathrm{X}$-ray diffraction patterns for the samples prepared through conventional sintering (1) and that prepared through microwave sintering at $1200^{\circ} \mathrm{C}(2), 1300^{\circ} \mathrm{C}$ (3) as starting temperature. It is evident that both samples exhibit $\mathrm{ZnO}$ phase (Z) with $\mathrm{ZnAl}_{2} \mathrm{O}_{4}$ phase (ZA) as the second phase from (1) and (2). But at $1300^{\circ} \mathrm{C}$ the XRD analysis shows only $\mathrm{ZnO}$ phase as shown in (3). The absence (presence in very low intensity) of the characteristic peaks of $\mathrm{ZnAl}_{2} \mathrm{O}_{4}$ may be explained by the melting of $\mathrm{ZnAl}_{2} \mathrm{O}_{4}$. The huge heat induced by microwave radiation and electricity at $1300^{\circ} \mathrm{C}$ turned $\mathrm{ZnAl}_{2} \mathrm{O}_{4}$ phase to amorphous state. Also, we can see that the intensity of the diffraction peaks for the sample prepared through microwave sintering is lower than that prepared through conventional sintering, which can be explained as the fact that the rapid heating of microwave prevented the growth of grain size. 


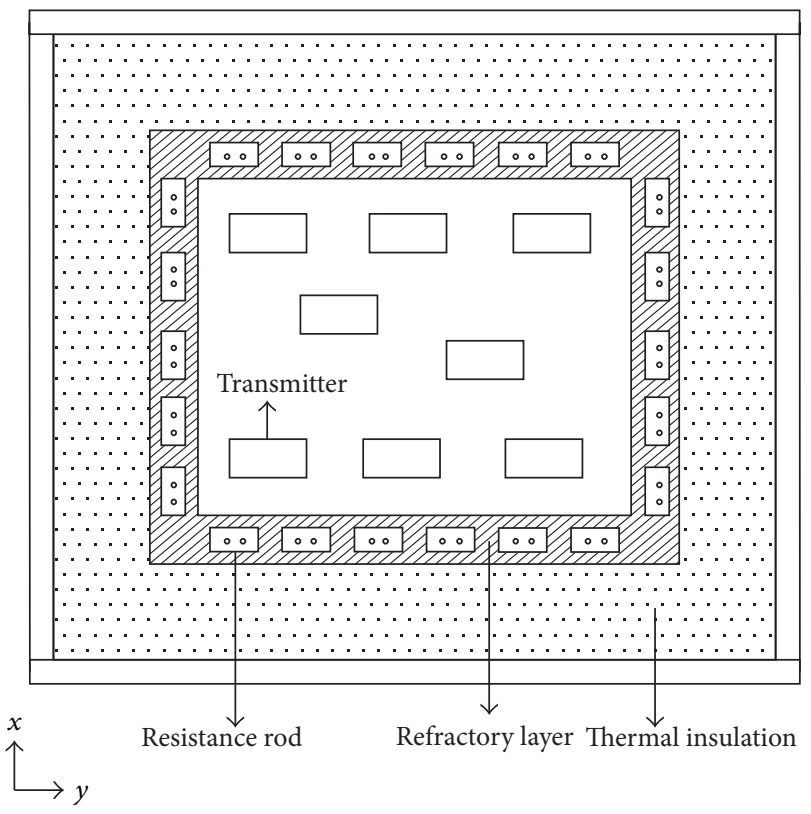

(a)

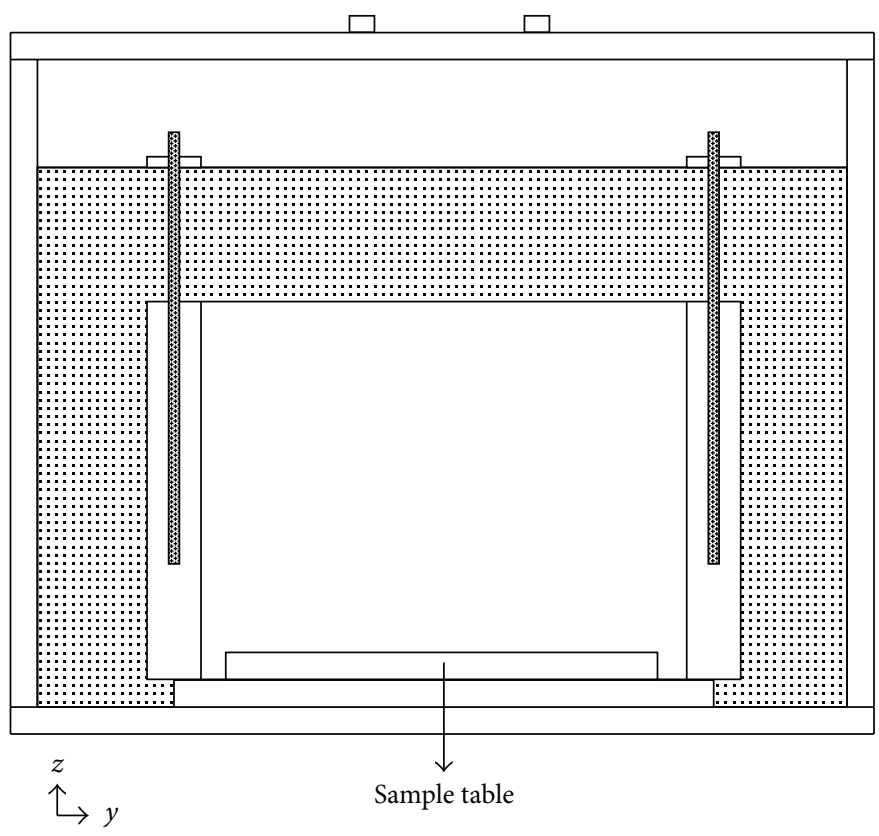

(b)

Figure 5: A schematic view of the furnace: (a) in $x-y$ view; (b) in $y-z$ view.

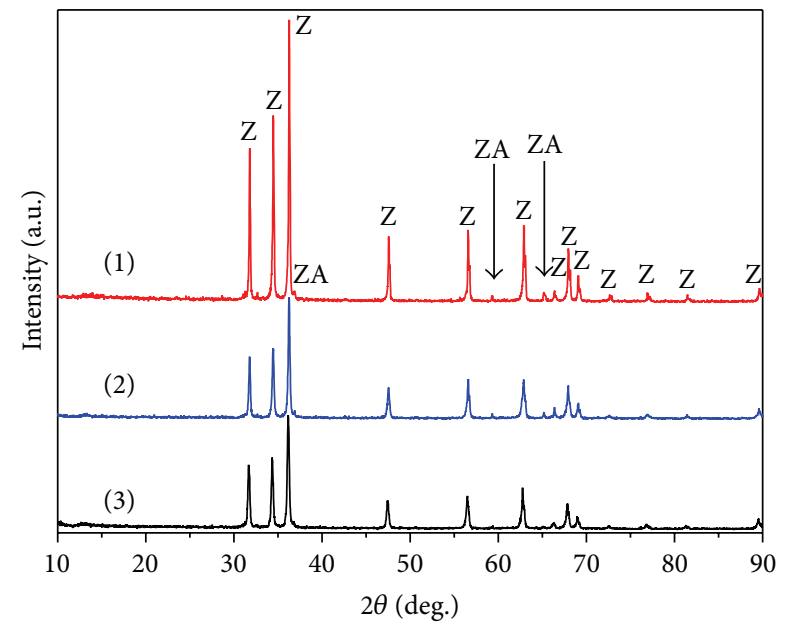

$\mathrm{Z}: \mathrm{ZnO}$ phase

$\mathrm{ZA}: \mathrm{ZnAl}_{2} \mathrm{O}_{4}$ phase

FIGURE 6: X-ray diffraction patterns for the AZO sample prepared through (1) conventional sintering, (2) (3) microwave sintering started at $1200^{\circ} \mathrm{C}, 1300^{\circ} \mathrm{C}$.

Figure 7 shows the microstructures of the AZO targets sintered at different starting temperatures for microwave heating. The average grain size of the sintered samples was estimated from the pictures using the linear intercept method [22]. The results are summarized in Table 2. The grain size increased from sample (a) to sample (d) with increasing microwave heating start temperatures. The starting temperature of microwave heating could alter the grain growth, such
TABLE 2: The grain size of microwave sintered samples.

\begin{tabular}{lc}
\hline Sample & Grain size $(\mu \mathrm{m})$ \\
\hline $\mathrm{a}$ & 8.3 \\
$\mathrm{~b}$ & 12.1 \\
$\mathrm{c}$ & 22.5 \\
$\mathrm{~d}$ & 28.4 \\
\hline
\end{tabular}

that the grains grow with increases in the starting temperature. The pictures also show that sample (c), with a start temperature of $1200^{\circ} \mathrm{C}$, has fewer pores and a smaller average grain size than the other samples do.

Figure 8 reveals the fracture morphology of the AZO targets sintered at different microwave starting temperatures. The pore sizes in samples (a), (b), and (c) are greater than those in sample (d). Comparing samples (a), (b), (c), and (d) in Figure 8 we note the absence of the second-phase $\mathrm{ZnAl}_{2} \mathrm{O}_{4}$, which is confirmed by XRD study in Figure 6.

Figure 9 shows the variation of the relative density of the target in different microwave starting temperatures. The relative density could increase to $98 \%$ when the microwave starting temperature was raised to $1200^{\circ} \mathrm{C}$. After this maximum, the relative density decreased with increases in the microwave starting temperature. According to the computational simulation, this result may be explained by the development of a high-intensity electromagnetic field around the sample. The temperature was raised rapidly by a large amount of heat generated from interactions between the electromagnetic field and the sample, which would increase the surface evaporation of $\mathrm{ZnO}$. The reduction of $\mathrm{ZnO}$ would decrease the relative density of the target. 

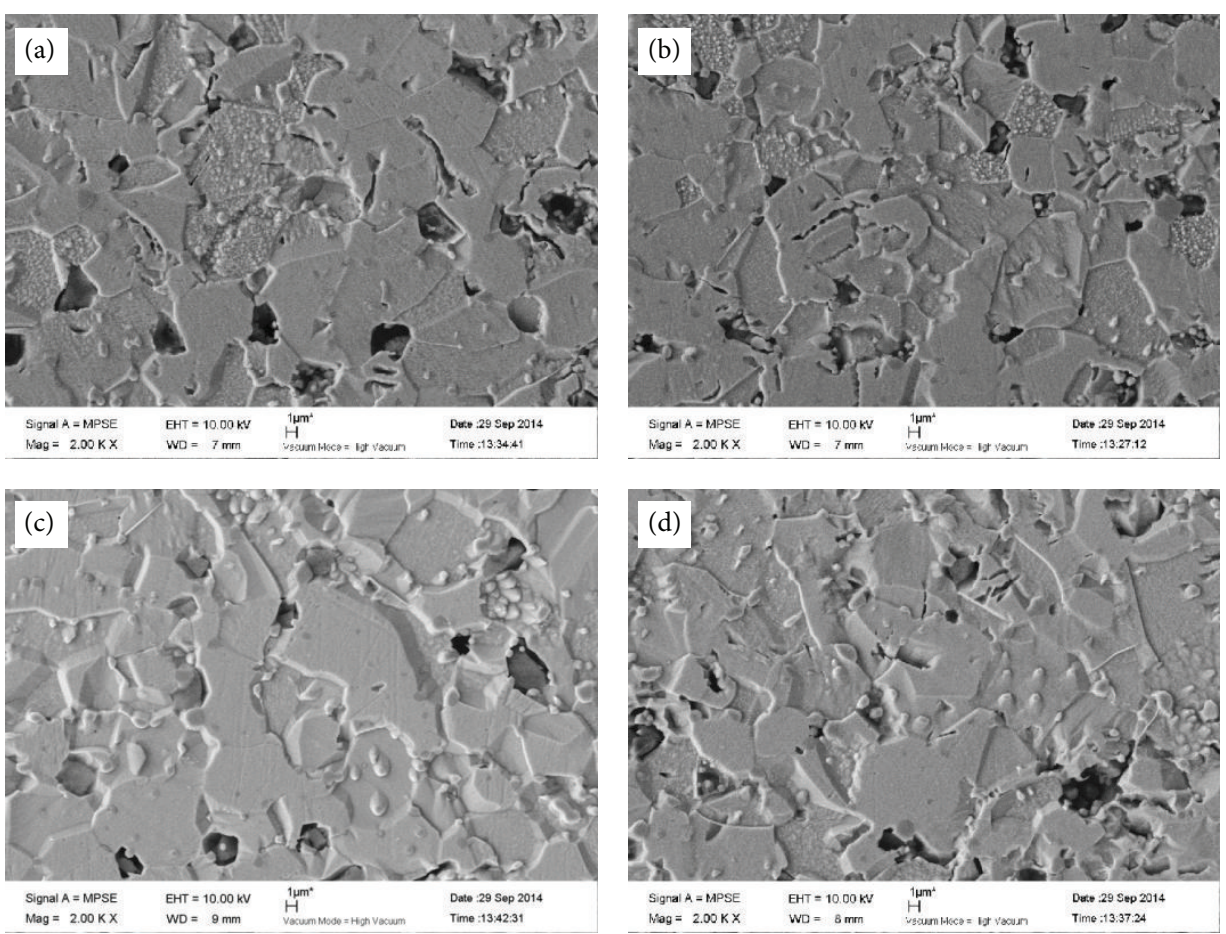

FIGURE 7: Microstructures of AZO targets sintered at different microwave starting temperatures: (a) 1000, (b) 1100, (c) 1200, and (d) $1300^{\circ} \mathrm{C}$.
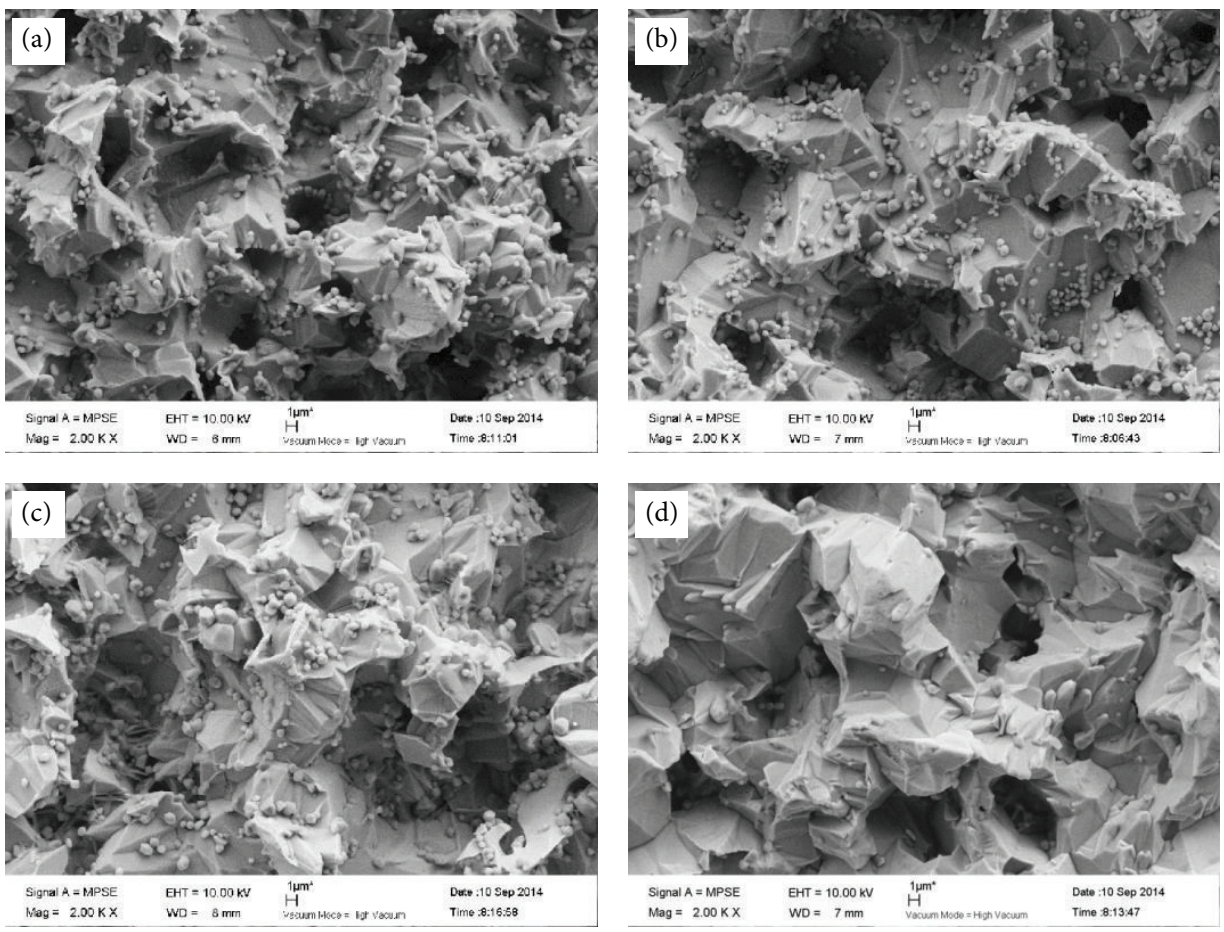

FIGURE 8: Fracture morphologies of AZO targets at different microwave starting temperatures: (a) $1000^{\circ} \mathrm{C}$, (b) $1100^{\circ} \mathrm{C},(\mathrm{c}) 1200^{\circ} \mathrm{C}$, and (d) $1300^{\circ} \mathrm{C}$. 


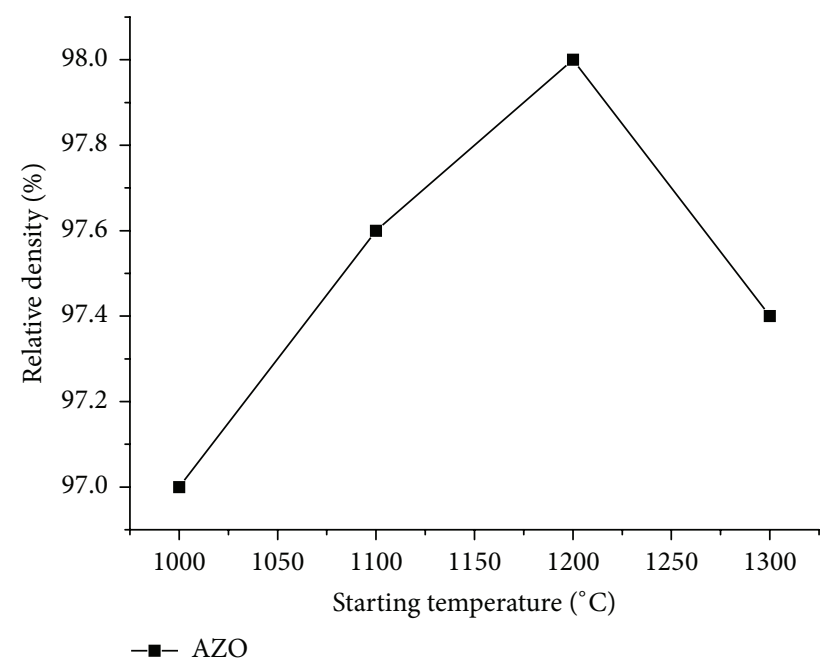

Figure 9: Relative densities of AZO targets as a function of microwave starting temperature.

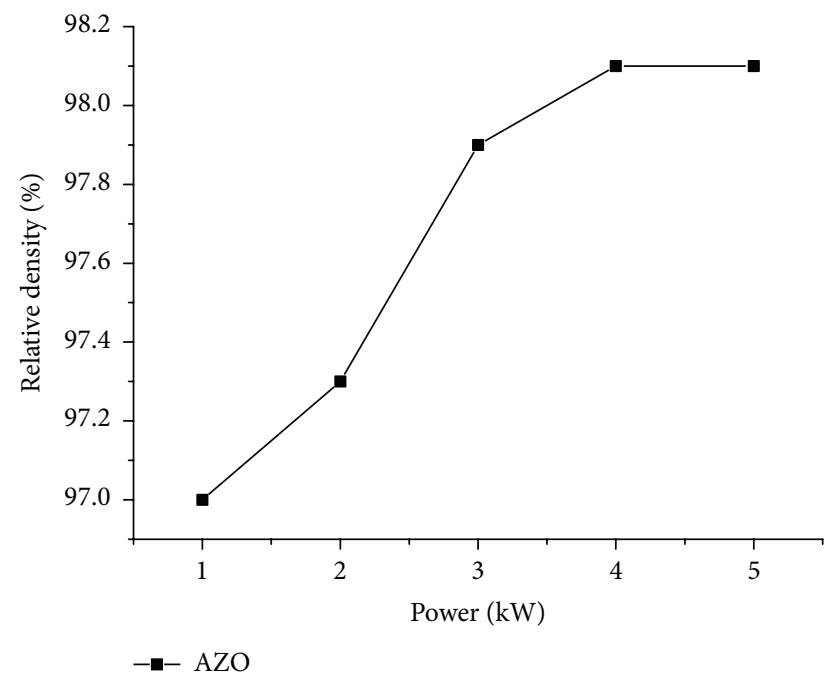

Figure 10: Relative densities of AZO targets as a function of microwave power.

All the above data show that $1200^{\circ} \mathrm{C}$ is the optimal temperature at which microwave heating should begin during the sintering of the AZO target.

4.2. Effect of Microwave Power on the Sintering of AZO Ceramic Target. As shown in Figure 10, the relative density of AZO target increased with increasing microwave power. When the microwave power was $4 \mathrm{~kW}$, the relative density was $98.1 \%$ and remaining constant with further power increases. This may be caused by the increased energy of the electromagnetic field with increased microwave power, which would produce heat, promoting powder aggregation and decreasing the size of pores in the ceramic in rapid time. As the active energy for powder aggregation increases as a function of the sintering temperature, once the energy required for powder aggregation exceeded the microwave radiation

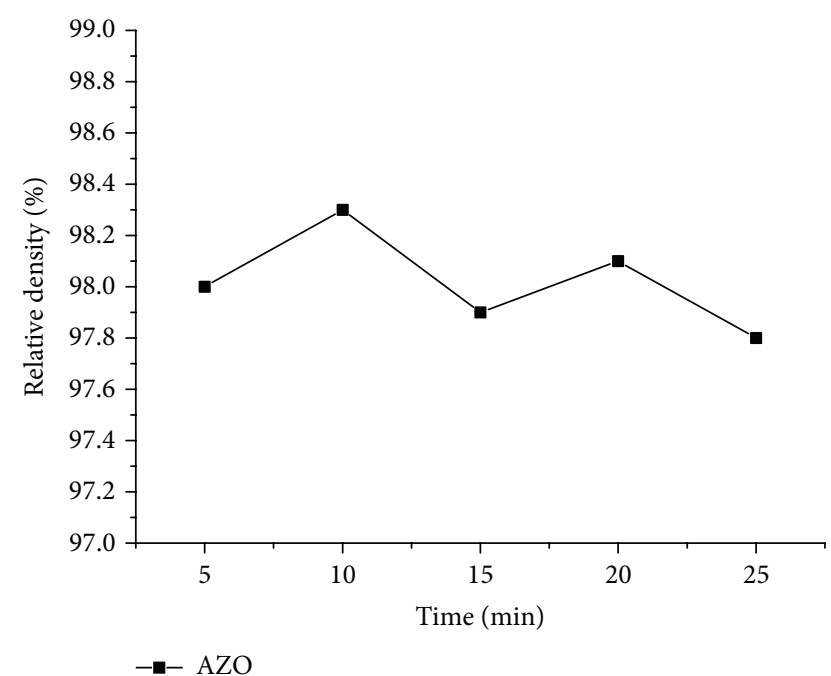

FIGURE 11: Relative densities of AZO targets as a function of change rate of microwave power.

energy, the powder aggregation process would be prevented by the high active energy; thus the ceramic density would remain constant.

4.3. Effect of Change Rate of Microwave Power during the Sintering Process. Figure 11 shows the relative densities of the different samples as a function of change rate of microwave power. The change in relative density was very small with the increase in change rate of microwave power, which correlated with the observation that the microwave heating rate had little effect on the density [16]. According to the study of Rahaman and Chu et al. [23, 24], the ceramic density was not affected by factors other than the sintering temperature.

Figure 12 displays photos of the AZO targets after sintering under different change rates of microwave power. Some obvious cracks occurred at the border of sample (a) and severe oversintering was visible on the surface. No cracks were found on the surfaces of sample (b) or (c). However, the sintering of (b) and (c) was inhomogeneous, as indicated by different surface colours. Sample (d) revealed homogeneous sintering without cracks on the sample surface. A comparison of these samples indicated that sintering was inhomogeneous and the target could crack when the microwave power changed too quickly. This may be because rapid increases in microwave power caused similarly rapid increases in temperature, resulting in a large amount of heat at the sintering area of the AZO target. The dramatic temperature gradient in the area could cause thermal stress in the target. Thermal stress was the main reason for the inhomogeneous sintering. So taking control of change rate of microwave power is necessary for a high-quality target.

4.4. Electrical Properties. Table 3 shows the resistivities of AZO targets prepared with microwave assistance at the starting temperatures of $1000-1300^{\circ} \mathrm{C}$. The results indicated that the resistivities of AZO targets sintered with microwave assistance decreased from $7.2 \times 10^{-2} \Omega \cdot \mathrm{cm}$ to $2.8 \times 10^{-3} \Omega \cdot \mathrm{cm}$ 


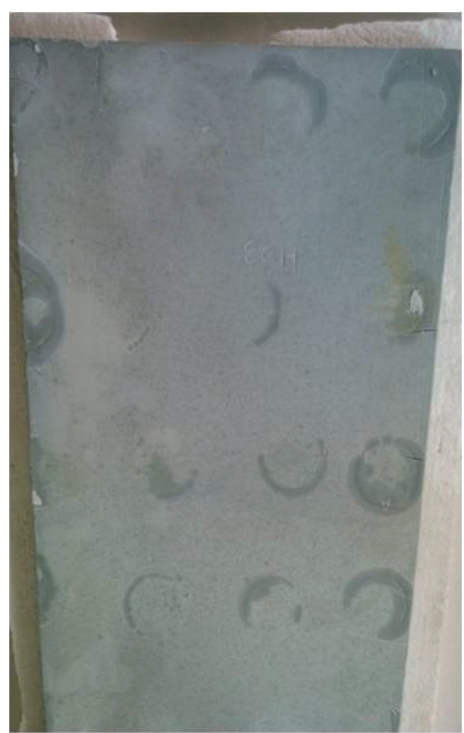

(a) $5 \mathrm{~min}$

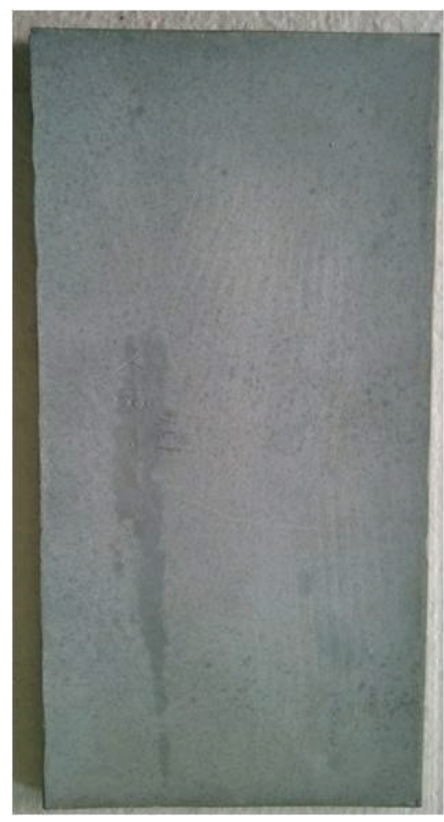

(c) $15 \mathrm{~min}$

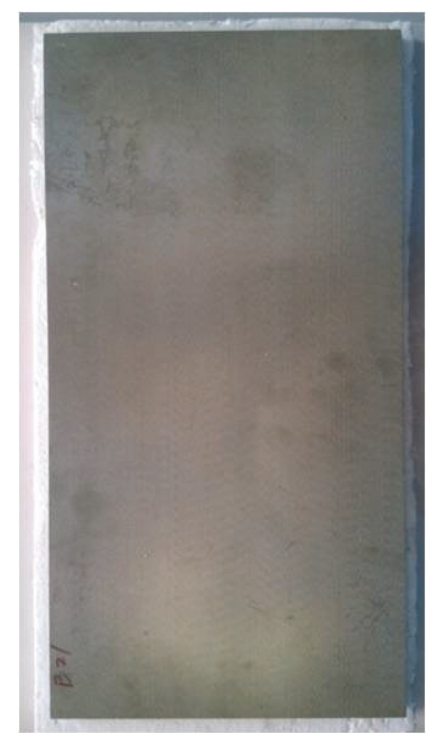

(b) $10 \mathrm{~min}$

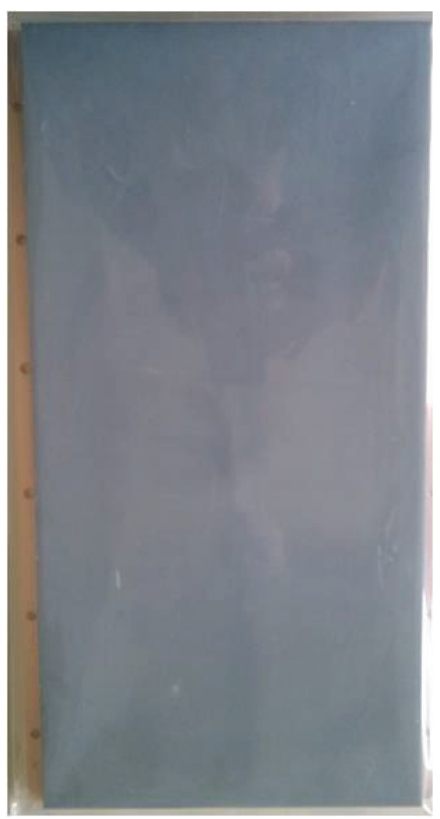

(d) $20 \mathrm{~min}$

FIGURE 12: Photographs of AZO targets after sintering with different change rates of microwave power.

TABLE 3: Resistivities of AZO targets.

\begin{tabular}{lcc}
\hline Sample & Microwave starting temperature $\left({ }^{\circ} \mathrm{C}\right)$ & Resistivity $(\Omega \cdot \mathrm{cm})$ \\
\hline 1 & 1000 & $7.2 \times 10^{-2}$ \\
2 & 1100 & $5.1 \times 10^{-2}$ \\
3 & 1200 & $2.8 \times 10^{-3}$ \\
4 & 1300 & $5.3 \times 10^{-3}$ \\
\hline
\end{tabular}

with the starting temperature raised from $1000^{\circ} \mathrm{C}$ to $1200^{\circ} \mathrm{C}$. When the temperature was raised to $1300^{\circ} \mathrm{C}$, the resistivity increased to $5.3 \times 10^{-3} \Omega \cdot \mathrm{cm}$. The variation of resistivities can be attributed to the sintered densities as shown in Figure 9. The lower sintered density led to serious scattering of electrons by the large amounts of pores in the targets. When the microwave starting temperature was increased from $1000^{\circ} \mathrm{C}$ to $1200^{\circ} \mathrm{C}$, the increase in sintered density and the change in pores alleviated the scattering of electrons, resulting in the increase of the resistivity. Moreover, as the formation of $\mathrm{ZnAl}_{2} \mathrm{O}_{4}$ phase, the $\mathrm{Al}$ dopant may gradually become more active as a conducting carrier between $1000^{\circ} \mathrm{C}$ and $1200^{\circ} \mathrm{C}$. But with the absence of $\mathrm{ZnAl}_{2} \mathrm{O}_{4}$ phase and the decrease in sintered density after the starting temperature was raised to $1300^{\circ} \mathrm{C}$, the resistivity increased slightly. 


\section{Conclusions}

(1) FEM simulation indicated that a homogeneous electric field distribution for sintering could be achieved by designing a microwave furnace with proper constraints. The sintering field increased in homogeneity with a multisource microwave relative to that achieved by a single-source microwave at high temperature. The sintering time could be reduced by using a multisource microwave instead of a singlesource microwave.

(2) By preparing the AZO target of $120 \times 240 \times 12 \mathrm{~mm}$ with microwave and electric hybrid sintering, the microwave starting temperature was found to affect the densification of the AZO target. Increasing the microwave power could increase the density of the AZO target. The change rate of microwave power had no obvious effect on the density of the target but significant effects on the integrity and uniformity of the large-sized AZO target.

(3) Based on the experimental results, an AZO target of $120 \times 240 \times 12 \mathrm{~mm}$ with a relative density of $98.1 \%$ can be obtained by introducing microwave power when the sample has reached $1200^{\circ} \mathrm{C}$ by electrical heating, with the output power increased to $4 \mathrm{~kW}$ in $20 \mathrm{~min}$.

(4) The resistivity of AZO targets sintered with microwave started at $1200^{\circ} \mathrm{C}$ could be as low as $2.8 \times$ $10^{-3} \Omega \cdot \mathrm{cm}$.

\section{Competing Interests}

The authors declare that there are no competing interests regarding the publication of this paper.

\section{Acknowledgments}

The authors are grateful for financial support from the National High Technology Research and Development Program of China (2012AA03030315).

\section{References}

[1] X. T. Hao, F. R. Zhu, K. S. Ong, and L. W. Tan, “Hydrogenated aluminium-doped zinc oxide semiconductor thin films for polymeric light-emitting diodes," Semiconductor Science and Technology, vol. 21, no. 1, pp. 48-54, 2006.

[2] C. G. Granqvist, "Transparent conductors as solar energy materials: a panoramic review," Solar Energy Materials and Solar Cells, vol. 91, no. 17, pp. 1529-1598, 2007.

[3] T. Minami, "Present status of transparent conducting oxide thin-film development for Indium-Tin-Oxide (ITO) substitutes," Thin Solid Films, vol. 516, no. 17, pp. 5822-5828, 2008.

[4] X. Yu, X. M. Yu, J. J. Zhang, and H. J. Pan, “Gradient Al-doped $\mathrm{ZnO}$ multi-buffer layers: effect on the photovoltaic properties of organic solar cells," Materials Letters, vol. 161, pp. 624-627, 2015.

[5] B. Hwang, Y.-K. Paek, S.-H. Yang, S. Lim, W.-S. Seo, and K.$\mathrm{S}$. Oh, "Densification of Al-doped $\mathrm{ZnO}$ via preliminary heat treatment under external pressure," Journal of Alloys and Compounds, vol. 509, no. 27, pp. 7478-7483, 2011.
[6] T. Minami, "Substitution of transparent conducting oxide thin films for indium tin oxide transparent electrode applications," Thin Solid Films, vol. 516, no. 7, pp. 1314-1321, 2008.

[7] G. Fang, D. Li, and B.-L. Yao, "Fabrication and vacuum annealing of transparent conductive AZO thin films prepared by DC magnetron sputtering," Vacuum, vol. 68, no. 4, pp. 363-372, 2002.

[8] M.-W. Wu, "Two-step sintering of aluminum-doped zinc oxide sputtering target by using a submicrometer zinc oxide powder," Ceramics International, vol. 38, no. 8, pp. 6229-6234, 2012.

[9] H. Cheng, X. J. Xu, H. H. Hng, and J. Ma, "Characterization of Al-doped $\mathrm{ZnO}$ thermoelectric materials prepared by RF plasma powder processing and hot press sintering," Ceramics International, vol. 35, no. 8, pp. 3067-3072, 2009.

[10] X.-M. Wang, X. Bai, H.-Y. Duan et al., "Preparation of Al-doped $\mathrm{ZnO}$ sputter target by hot pressing," Transactions of Nonferrous Metals Society of China, vol. 21, no. 7, pp. 1550-1556, 2011.

[11] J. Zhang, W. Zhang, E. Zhao, and H. J. Jacques, "Study of highdensity AZO ceramic target," Materials Science in Semiconductor Processing, vol. 14, no. 3-4, pp. 189-192, 2011.

[12] H. Bouhamed and S. Baklouti, "Synthesis and characterization of $\mathrm{Al}_{2} \mathrm{O}_{3} / \mathrm{Zno}$ nanocomposite by pressureless sintering," Powder Technology, vol. 264, pp. 278-290, 2014.

[13] D. E. Clark and W. H. Sutton, "Microwave processing of materials," Annual Review of Materials Science, vol. 26, no. 1, pp. 299-331, 1996.

[14] J. D. Katz and R. D. Blake, "Microwave sintering of multiple alumina and composite components," American Ceramic Society Bulletin, vol. 67, pp. 1304-1308, 1991.

[15] Z. Xie, J. Yang, X. Huang, and Y. Huang, "Microwave processing and properties of ceramics with different dielectric loss," Journal of the European Ceramic Society, vol. 19, no. 3, pp. 381-387, 1999.

[16] R. F. K. Gunnewiek and R. H. G. A. Kiminami, "Effect of heating rate on microwave sintering of nanocrystalline zinc oxide," Ceramics International, vol. 40, no. 7, pp. 10667-10675, 2014.

[17] A. Birnboim, D. Gershon, J. Calame et al., "Comparative study of microwave sintering of zinc oxide at $2.45,30$, and $83 \mathrm{GHz}$," Journal of the American Ceramic Society, vol. 81, no. 6, pp. 14931501, 1998.

[18] M. A. Janney and H. D. Kimrey, "Microstructure evolution in microwave sintered alumina," in Ceramic Powder Science, Vol. II, pp. 919-924, American Ceramic Society, 1988.

[19] M. A. Janney, C. L. Calhoun, and H. D. Kimrey, "Microwave sintering of zirconia-8 mol\% yttria," Ceramic Transactions, vol. 21, pp. 311-318, 1991.

[20] D. C. Dibben and A. C. Metaxas, "Finite element time domain analysis of multimode applicators using edge elements," Journal of Microwave Power \& Electromagnetic Energy, vol. 29, no. 4, pp. 242-251, 1994.

[21] A. K. Shukla, A. Mondal, and A. Upadhyaya, "Numerical modeling of microwave heating," Science of Sintering, vol. 42, no. 1, pp. 99-124, 2010.

[22] J. C. Wurst and J. A. Nelson, "Lineal intercept technique for measuring grain size in two-phase polycrystalline ceramics," Journal of the American Ceramic Society, vol. 55, no. 2, p. 109, 1972.

[23] M. N. Rahaman, Ceramic Processing and Sintering, Taylor \& Francis, New York, NY, USA, 2nd edition, 2003.

[24] M. Y. Chu, N. Rahaman, L. C. Jonghe, and R. J. Brook, "Effect of heating rate on sintering and coarsening," Journal of the American Ceramic Society, vol. 74, no. 6, pp. 1217-1225, 1991. 

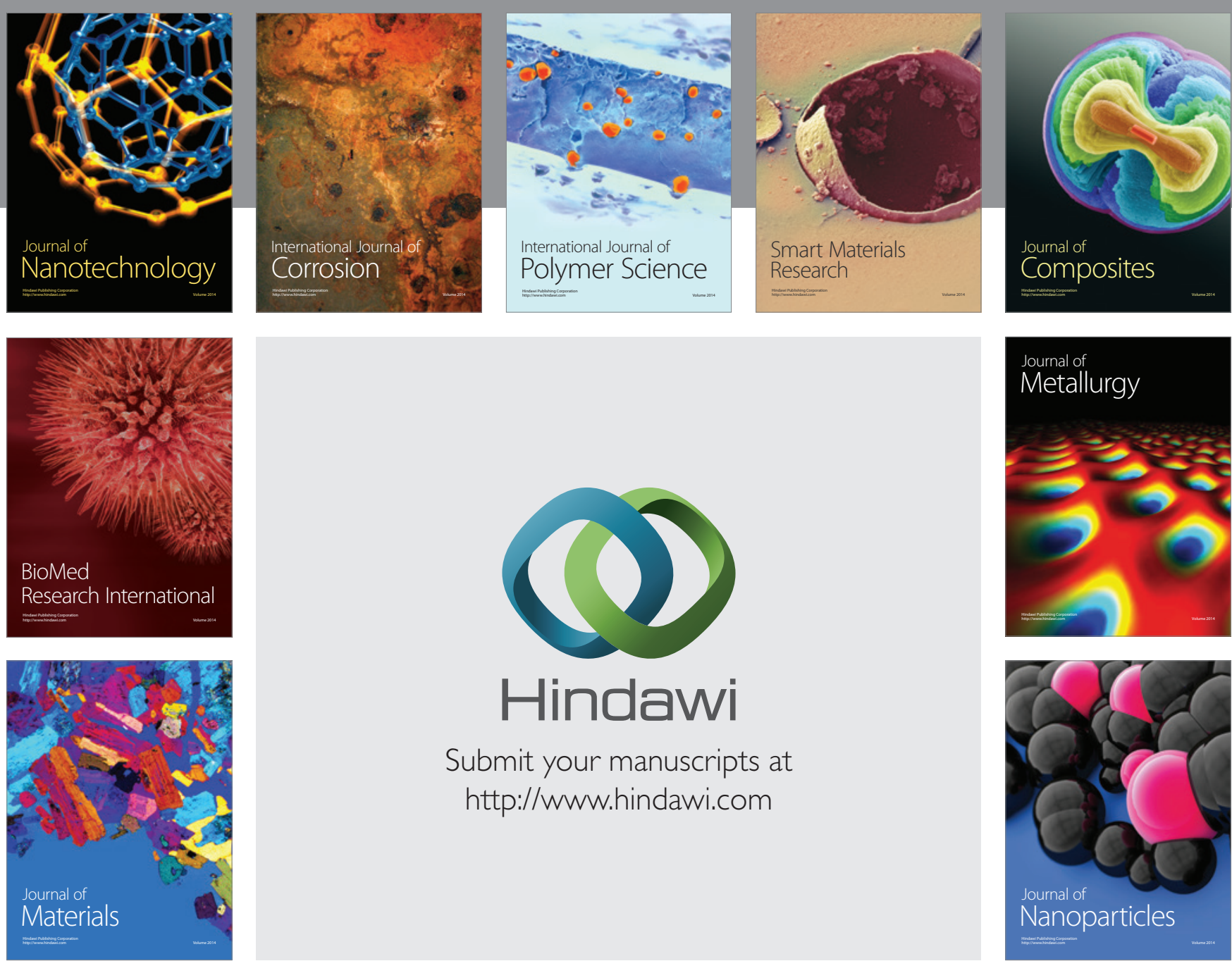

\section{Hindawi}

Submit your manuscripts at

http://www.hindawi.com

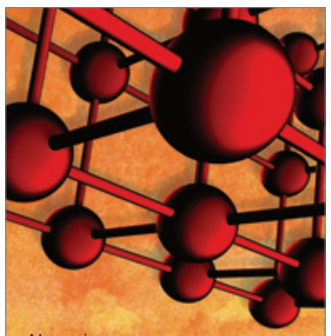

Materials Science and Engineering
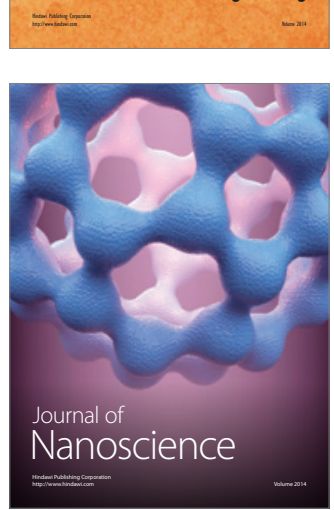
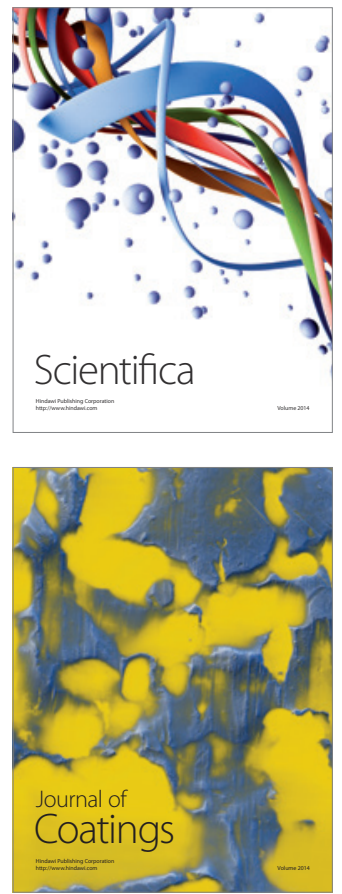
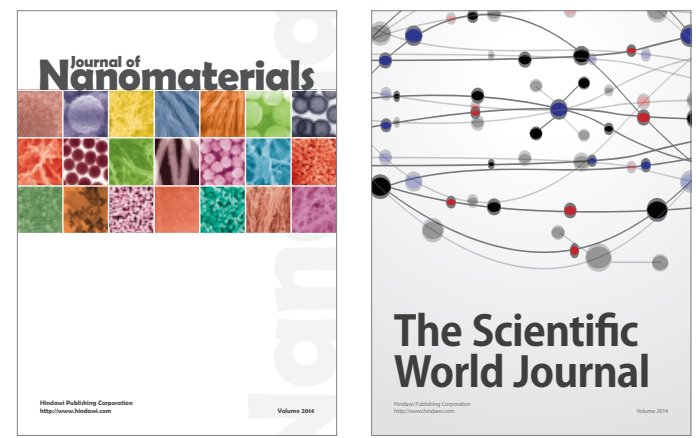

The Scientific World Journal
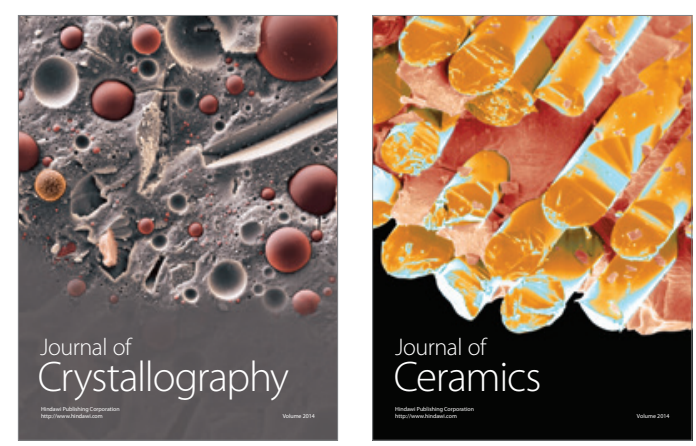
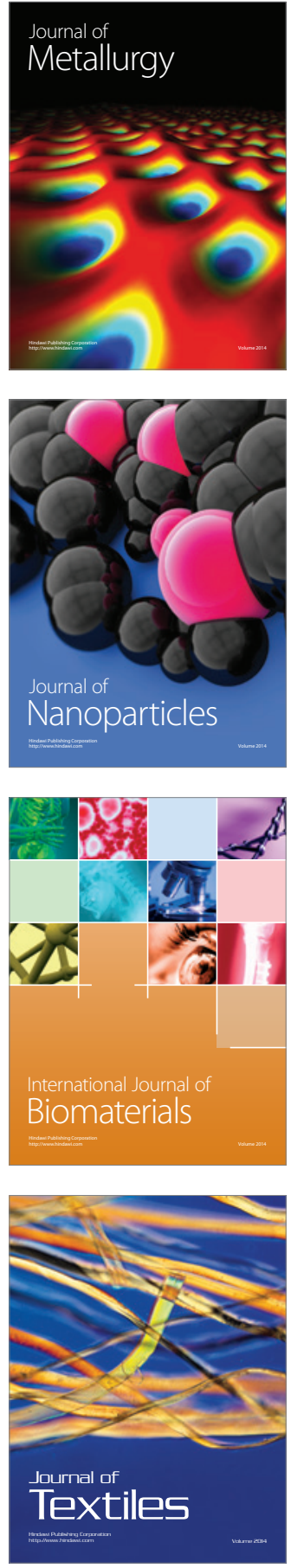